\title{
BMJ Open Prevalence of key breastfeeding indicators in 29 sub-Saharan African countries: a meta-analysis of demographic and health surveys (2010- 2015)
}

Abukari Ibrahim Issaka, ${ }^{1}$ Kingsley Emwinyore Agho, ${ }^{2}$ Andre MN Renzaho ${ }^{1}$

To cite: Issaka Al, Agho KE, Renzaho AMN. Prevalence of key breastfeeding indicators in 29 sub-Saharan African countries: a meta-analysis of demographic and health surveys (2010-2015). BMJ Open 2017;7:e014145. doi:10.1136/ bmjopen-2016-014145

- Prepublication history and additional material for this paper are available online. To view please visit the journal (http:// dx.doi.org/10.1136/bmjopen2016-014145).

Received 5 September 2016 Revised 24 May 2017 Accepted 30 June 2017

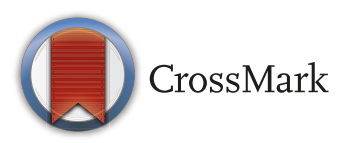

${ }^{1}$ School of Social Sciences and Psychology, Western Sydney University, Sydney, New South Wales, Australia

${ }^{2}$ School of Science and Health, Western Sydney University, Sydney, New South Wales, Australia

Correspondence to Dr Abukari Ibrahim Issaka; ib12097@gmail.com

\section{ABSTRACT}

Objectives To carry out a meta-analysis to assess the prevalence of four key breastfeeding indicators in four subregions of 29 sub-Saharan African countries.

Design, settings and participants The 29 countries were categorised into four subregions, and using crosssectional data from the most recent Demographic and Health Surveys (2010-2015) of these countries prevalence of each of four key breastfeeding indicators was estimated for each of the subregions by carrying out a meta-analysis. Due to the presence of significant heterogeneity among the various surveys $\left(I^{2}>50 \%\right)$, a random-effect analytic model was used, and sensitivity analysis was performed to examine the effects of outliers.

Main outcome variables Early initiation of breast feeding, exclusive breast feeding, predominant breast feeding and bottle feeding.

Results The overall prevalence of early initiation of breast feeding varied between a lowest of $37.84 \%(95 \% \mathrm{Cl}$ 24.62 to 51.05 ) in Central Africa to a highest of $69.31 \%$ (95\% Cl 67.65 to 70.97 ) in Southern Africa; the overall prevalence of exclusive breast feeding ranged between a lowest of $23.70 \%$ (95\% Cl 5.37 to 42.03 ) in Central Africa to a highest of $56.57 \%(95 \% \mathrm{Cl} 53.50$ to 59.95$)$ in Southern Africa; the overall prevalence of predominant breast feeding ranged between a lowest of $17.63 \%$ (95\% Cl 12.70 to 22.55$)$ in East Africa and a highest of $46.37 \%(95 \% \mathrm{Cl} 37.22$ to 55.52$)$ in West Africa; while the prevalence of bottle feeding varied between a lowest of $8.17 \%(95 \% \mathrm{Cl} 5.51$ to 10.84$)$ in West Africa and a highest of $30.05 \%$ (95\% Cl 28.42 to 31.69 ) in Southern Africa. Conclusions West Africa and Central Africa recorded lower overall prevalence of early initiation of breast feeding and exclusive breast feeding than the WHO's recommended target of $50 \%$ by the year 2025 . Intervention for improved breastfeeding practices in subSaharan Africa should target West and Central Africa, while intervention to minimise bottle feeding should target Southern Africa.

\section{INTRODUCTION}

For a baby to grow and develop to its full potential, the baby needs the right foods at
Strengths and limitations of this study

- The prevalence of the four key breastfeeding indicators was based on 29 nationally representative surveys, and therefore findings across the subregion could be generalised.

- Data of the study were from population-based surveys of the countries examined.

- Variables of the Demographic and Health Surveys are similarly defined across countries and thus comparable across the countries.

- Due to the cross-sectional design of the study, inferences on causes and effects could not be substantiated.

- There could be a poor maternal recall of breastfeeding duration.

the right time. ${ }^{1}$ The crucial time for good nutrition of a baby is between the inception of pregnancy of a woman and the second birthday of a child, which is usually referred to as the 'critical window' and which is approximately 1000 days. $^{2}$ The best food for a child's growth and development during this critical window is breast milk. All of the vitamins, minerals, enzymes and antibodies needed by a child to grow and thrive are provided by breast milk. ${ }^{2}$ Breast milk is safe, as it is always at the appropriate temperature, does not require any preparation and is available even in environments where there is poor sanitation and unsafe drinking. ${ }^{1}$

The act of feeding a baby with a mother's breast milk is referred to as breast feeding. Breast feeding has many health benefits for an infant and has been reported to be an unequalled way of provision of ideal food for an infant's healthy growth and development ${ }^{3}$, as well as reduction of infant morbidity and mortality and prevention of long-term chronic diseases. ${ }^{45}$ Breast feeding can be beneficial to 


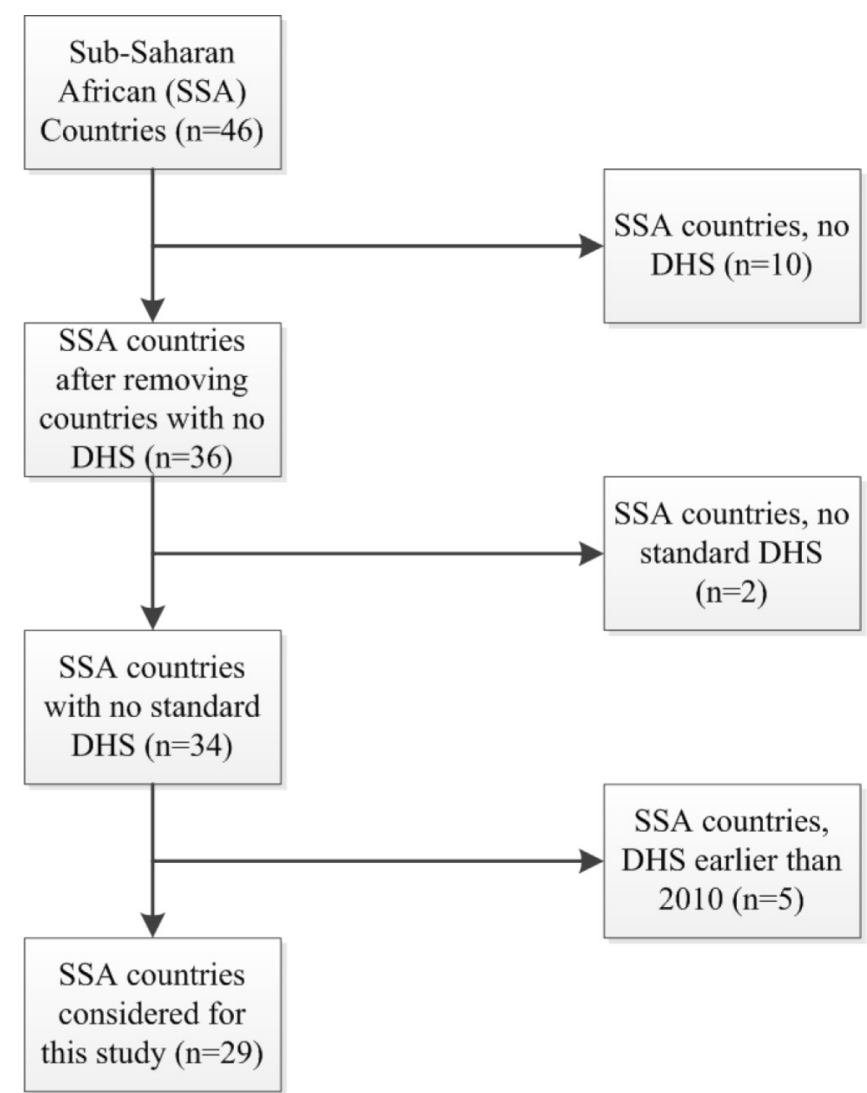

Figure 1 Flow scheme for country selection based on the exclusion and inclusion criteria. DHS, Demographic and Health Surveys.

the mother, as it helps in preventing postpartum haemorrhage, reduces the risk of breast and ovarian cancers, and allows better spacing of pregnancies among women. ${ }^{1}$

Three indicators constitute optimal breast feeding among women. These are (1) early initiation of breast feeding (EIBF) (the practice of providing a mother's breast milk to infants within 1 hour of delivery), ${ }^{6}$ which ensures that the infant receives the colostrum of the 'first milk' that is rich in protective factors; (2) exclusive breast feeding (EBF) (no additional foods or liquids, including water, except vitamin supplements and medicines) for 6 months; and (3) continued breast feeding at 1 year (CBF1) (includes breast feeding by a wet nurse and feeding expressed breast milk). These three indicators are the most critical for population-based assessment and programme evaluation. $^{7}$ Other optional breastfeeding indicators include predominant breast feeding under 6 months (PBF) (giving breast milk and other fluids) and bottle feeding (BTLF). BTLF is defined as the act of giving an infant any food or drink, including breast milk, from a bottle with a nipple/ teat, regardless of whether they are breast fed or not. ${ }^{8}$

While EIBF, EBF and CBF1 offer protective effects to the infant, ${ }^{9-11}$ PBF and BTLF offer risk effects. ${ }^{12} 13$ This is because since PBF and BTLF may involve other fluids such as water, the likelihood of increased diarrhoea-related morbidity and mortality is high.
In the low-income/middle-income countries, only $39 \%$ of children aged less than 6 months are exclusively breast fed, and just about $58 \%$ of children 20-23 months old benefit from the practice of continued breast feeding, ${ }^{14}$ which highlights the poor overall breastfeeding practices in the world. Past research suggests that initiation of breast feeding within the first hour of birth may lead to the prevention of about $20 \%$ of neonatal deaths. ${ }^{815} \mathrm{In}$ low-income/middle-income countries, optimal breast feeding has the potential of preventing $12 \%$ of all under-5 deaths. ${ }^{16}$ Children who are exclusively breast fed have been shown to be less susceptible to diarrhoeal diseases and pneumonia, and are 14 times more likely to survive, compared with those who are not breast fed. ${ }^{17}$

There are a number of past studies on breastfeeding practices in Africa. ${ }^{18-23}$ None of the studies, however, has specifically examined the prevalence of the breastfeeding indicators in any subregion of Africa. In this current study, 29 countries in sub-Saharan Africa were categorised into four subregions, namely West Africa, East Africa, Central Africa and Southern Africa. A meta-analysis of four key breastfeeding indicators for each of the four subregions was carried out by using the most recent nationally representative Demographic and Health Surveys (DHS) (between 2010 and 2015) of the countries examined. The objective of the categorisation was to highlight the four subregions in order to identify subregions that needed intervention the most, to improve the protective indicators and to minimise the risk indicators.

Results of this study will establish the effectiveness or otherwise of programmes such as the LINKAGES project, which was funded by the United States Agency for International Development (USAID) to identify subregions in sub-Saharan Africa that registered low prevalence of appropriate breast feeding. The results of this study could also enable stakeholders and policy makers to implement interventions that could rapidly improve the behaviour of people and standard of communities with respect to issues concerning early and exclusive breast feeding at a scale that could achieve significant public health impact.

\section{METHODS}

\section{Data sources}

The data sources used in this meta-analysis were the most recent DHS of the countries surveyed (between 2010 and 2015). There are 54 recognised countries that make up the African continent. These countries are member states of the African Union. ${ }^{24}$ Geographically, sub-Saharan Africa is the area of the continent of Africa lying south of the Sahara desert. According to the United Nations (UN), sub-Saharan Africa consists of all African countries that are fully or partially located south of the Sahara. The UN Development Program lists 46 out of the 54 African countries as part of sub-Saharan Africa, ${ }^{25}$ although the World Bank includes Somalia and Sudan to the list. ${ }^{26}$ In this study, 29 countries in the subregion met our selection 
criteria (sub-Saharan African countries that possessed DHS data sets between 2010 and 2015).

The data sets for these countries are in the public domain and are available from the DHS Program website. ${ }^{27}$ The DHS data are large, cross-sectional and nationally representative.

The majority of the surveys apply a two-stage cluster sampling method. Due to the fact that the DHS surveys were intended to address household-based health issues, strata for urban and rural households were used for selection of respondents. Additionally, each DHS follows a standard procedure of data collection and presentation (similar questionnaires) and uses the same definition of terms. Detailed methodology of data collection by the DHS is described elsewhere. ${ }^{28}$ Our analysis used the sampling weights in accounting for each country-specific study design.

\section{Study selection and inclusion criteria}

The choice of countries included in the study was constrained by countries whose DHS data sets were recent and had information on breast feeding. After a critical examination of the DHS data sets, we obtained 29 countries whose DHS data were recent (last 5 years, between 2010 and 2015) (see figure 1). The countries were Benin, Burkina Faso, Burundi, Cameroon, Cote d'Ivoire, Comoros, Congo Brazzaville, Democratic Republic of Congo, Ethiopia, Gabon, Gambia, Ghana, Guinea, Kenya, Lesotho, Liberia, Malawi, Mali, Mozambique, Namibia, Niger, Nigeria, Rwanda, Senegal, Sierra Leone, Tanzania, Uganda, Zambia and Zimbabwe. Our selection criteria yielded a total of 116392 children aged 6-23 months.

\section{Questions asked in the DHS regarding primary outcomes}

Questions on breast feeding and nutrition cover feeding practices, the length of breast feeding, children's consumption of liquids and solid food, and micronutrient supplementation.

The following were some of the questions asked regarding the primary outcomes: 'Did you ever breastfeed?' 'Is the child living?' 'How long after birth did you first put (name) to the breast?' 'In the first three days after delivery, was (name) given anything to drink other than breast milk?' 'What was (name) given to drink?' 'Anything else?' 'Are you still breastfeeding (name)?' 'Did (name) drink anything from a bottle with a nipple yesterday or last night?' (see online supplementary appendix).

\section{The key breastfeeding indicators}

Four of the new and updated breastfeeding indicators recommended by the WHO were used in this study. ${ }^{7}$ Two of the indicators, namely EIBF and EBF, have protective effects, while the other two, namely PBF and BTLF, have risky effects. The indicators, which are based on 24-hour recall by mothers, are defined below ${ }^{29}$ :

1. EIBF: the proportion of children born in the last 24 months who were put to the breast within 1 hour of birth, expressed mathematically as:
Children born in the last 24 months

who were put to the breast within one

Children born in the last 24 months

2. EBF: the proportion of infants aged $0-5$ months who are fed exclusively with breast milk:

Infants $0-5$ months of age who received only breast milk during the previous day Infants $0-5$ months of age

3. PBF: the proportion of infants aged $0-5$ months who are predominantly breast fed:

\begin{tabular}{l} 
Infants $0-5$ months of age who received \\
breast milk as the predominant source \\
of nourishment during the previous day \\
\hline Infants $0-5$ months of age
\end{tabular}

4. BTLF: the proportion of children aged 0-23 months who are fed with a bottle: Children $0-23$ months of age who were
fed with a bottle during the previous day
Children $0-23$ months of age

Facts about BTLF are important to mothers as it has a tendency to potentially interfere with appropriate breastfeeding practices and also because BTLF is associated with increased diarrhoea-induced morbidity and mortality. Feeding bottles fitted with nipples are especially subject to contamination. A similar argument applies to PBF. Since PBF allows the infant to be given water and other liquids, there is a tendency of the water to be contaminated, and this may cause diarrhoeal disease.

\section{Statistical analysis}

Analyses were carried out using Stata/MP V.14. First, the survey tabulation 'svytab' command, which adjusts for stratification, cluster-sampling design and sampling weights, was used to compute the frequency count and total count for EIBF, EBF, PBF and BTLF from every country. Second, the 'metaprop' function/program ${ }^{30}$ in Stata was used to produce forest plots of the overall pooled prevalence and associated $95 \%$ CIs of EIBF, EBF, PBF and BTLF for each of the four subregions. The test for heterogeneity among the DHS data of the different countries uncovered inconsistencies $\left(\mathrm{I}^{2}>50 \%\right)$ in all the meta-analyses; therefore, we used the random-effects model. Metaprop implements procedures that are specific to binomial data, allows computation of exact binomial data and incorporates the Freeman-Tukey double arcsine transformation of proportions. ${ }^{31}$ The confidence limits for a binomial proportion are constructed by inverting the equal-tailed test based on the binomial distribution. ${ }^{32}$ Metaprop pools proportions and presents a weighted subgroup and overall pooled estimates with inverse-variance weights obtained from a random-effects model.

Sensitivity analyses were carried out to examine the effect of outliers by comparing the pooled prevalence before and after elimination of one country at a time, in line with the work of Patsopoulos and colleagues. ${ }^{33}$ 
Open Access

Table 1 Demographic information of the study countries

\begin{tabular}{|c|c|c|c|c|}
\hline Country & $\begin{array}{l}\text { Population } \\
\text { (million) (2013) }\end{array}$ & $\begin{array}{l}\text { Average GDP } \\
\text { (US\$) (2013) }\end{array}$ & $\begin{array}{l}\text { Gender ratio } \\
\text { (male:female) (2016) }\end{array}$ & $\begin{array}{l}\text { Life expectancy } \\
\text { (years) (2012) }\end{array}$ \\
\hline \multicolumn{5}{|l|}{ West Africa } \\
\hline Benin & 10.32 & 804.69 & 1.01 & 59.12 \\
\hline Burkina Faso & 16.93 & 683.95 & 0.99 & 55.86 \\
\hline Cote d'Ivoire & 20.32 & 1528.94 & 1.02 & 50.4 \\
\hline Gambia & 1.85 & 488.57 & 0.98 & 58.61 \\
\hline Ghana & 25.90 & 1858.24 & 0.97 & 60.95 \\
\hline Guinea & 11.75 & 523.12 & 1.00 & 55.84 \\
\hline Mali & 15.30 & 715.13 & 0.95 & 54.6 \\
\hline Niger & 17.83 & 415.42 & 1.01 & 57.97 \\
\hline Nigeria & 173.60 & 3005.51 & 1.04 & 52.11 \\
\hline Senegal & 14.13 & 1046.59 & 0.94 & 63.2 \\
\hline Sierra Leone & 6.09 & 678.96 & 0.95 & 45.33 \\
\hline Togo & 6.82 & 636.44 & 0.98 & 56.15 \\
\hline \multicolumn{5}{|l|}{ Central Africa } \\
\hline Cameroon & 22.25 & 1328.64 & 1.01 & 54.59 \\
\hline Congo Bra & 4.45 & 3167.05 & 1.01 & 58.3 \\
\hline Congo DR & 67.51 & 484.21 & 1.00 & 49.62 \\
\hline Gabon & 1.67 & 11571.08 & 0.99 & 63.07 \\
\hline \multicolumn{5}{|l|}{ East Africa } \\
\hline Burundi & 10.16 & 267.11 & 0.99 & 53.63 \\
\hline Comoros & 0.73 & 814.96 & 0.94 & 60.64 \\
\hline Ethiopia & 94.10 & 505.05 & 0.99 & 62.97 \\
\hline Kenya & 44.35 & 1245.51 & 1.00 & 61.08 \\
\hline Malawi & 16.36 & 226.46 & 0.98 & 54.72 \\
\hline Mozambique & 25.83 & 605.03 & 0.95 & 49.84 \\
\hline Rwanda & 11.78 & 638.67 & 0.99 & 63.49 \\
\hline Tanzania & 49.25 & 694.77 & 0.99 & 60.85 \\
\hline Uganda & 37.58 & 571.96 & 0.99 & 58.65 \\
\hline Zambia & 14.54 & 1844.8 & 1.00 & 57.02 \\
\hline Zimbabwe & 14.15 & 953.38 & 1.01 & 58.05 \\
\hline \multicolumn{5}{|l|}{ Southern Africa } \\
\hline Lesotho & 2.04 & 1125.59 & 0.98 & 48.84 \\
\hline Namibia & 2.3 & 5693.13 & 1.02 & 63.88 \\
\hline
\end{tabular}

Congo Bra, Congo Brazzaville; Congo DR, Demographic Republic; GDP, gross domestic product.

\section{RESULTS}

Some demographic information of the study countries are summarised in table 1 . The most populous country was Nigeria in West Africa, with a population of 173.60 million, a gross domestic product (GDP) of US\$3005.51 and a life expectancy of 52.11 years. The next most populous country was Ethiopia in East Africa, with a population of 94.10 million, a GDP of US\$505.05 and a life expectancy of 62.97 years. The least populous country was Comoros. Comoros had a population of 0.73 million, a GDP of US $\$ 814.96$ and a life expectancy of 60.64 years.
The overall prevalence of EIBF, EBF, PBF and BTLF for all 29 countries was $52.83 \%$ (95\% CI 43.31 to 62.36 ), $41.07 \%$ (95\% CI 32.97 to 49.17 ), $31.29 \%$ (95\% CI 23.87 to 38.71 ) and $13.19 \%$ (95\% CI 10.27 to 16.10 ), respectively.

\section{Early initiation of breast feeding}

Figure 2 is a forest plot of the prevalence of EIBF among infants aged 0-23 months in the 29 sub-Saharan African countries. The prevalence of EIBF for West Africa, East Africa, Central Africa and Southern Africa was $46.94 \%$ (95\% CI 39.37 to 54.50$), 61.82 \%$ (95\% CI 46.22 to 


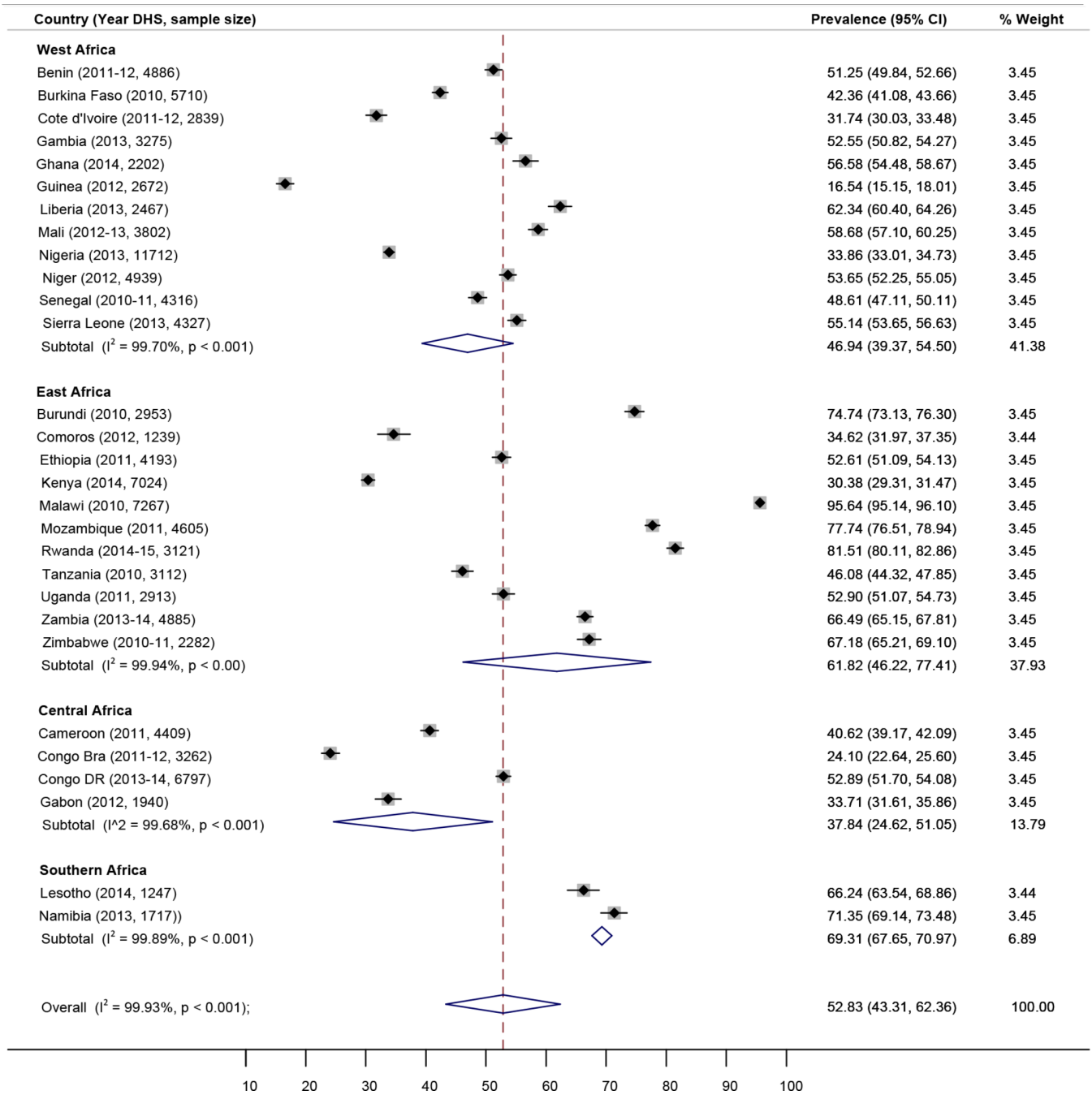

Figure 2 Prevalence of early initiation of breast feeding in 28 sub-Saharan African countries (2010-2015). Congo Bra, Congo Brazzaville; Congo DR, Democratic Republic of Congo; DHS, Demographic and Health Surveys.

$77.41), 37.84 \%$ (95\% CI 24.62 to 51.05$)$ and $69.31 \%$ (95\% CI 67.65 to 70.97$)$, respectively. Countries with the lowest prevalence of EIBF were Guinea (16.54\%) in West Africa, Kenya $(30.38 \%)$ in East Africa, Congo Brazzaville $(24.10 \%)$ in Central Africa and Lesotho (66.24\%) in Southern Africa.

\section{Exclusive breast feeding}

A forest plot of the prevalence of MDD for the 29 countries is shown in figure 3. The prevalence of EBF for West Africa, East Africa, Central Africa and Southern Africa was $32.64 \%$ (95\% CI 25.85 to 39.43 ), $53.48 \%$ (95\% CI 40.14 to $66.82), 23.70 \%$ (95\% CI 5.37 to 42.03$)$ and $56.57 \%$ (95\% CI 53.20 to 59.95), respectively. In West Africa, Cote d'Ivoire reported the lowest prevalence of EBF of $13.15 \%$. The corresponding prevalence reported in East Africa, Central Africa and Southern Africa was $13.45 \%$ (Comoros), $6.04 \%$ (Gabon) and 48.66\% (Namibia).

\section{Predominant breast feeding}

Figure 4 shows a forest plot of the prevalence of PBF for the 29 sub-Saharan African countries. The prevalence of PBF for West Africa, East Africa, Central Africa and Southern
Africa was $43.67 \%$ (95\% CI 37.22 to 55.52$)$, $17.63 \%$ (95\% CI 12.70 to 22.55$), 31.63 \%$ (95\% CI 19.77 to 43.48 ) and $13.07 \%$ (95\% CI 10.77 to 15.38 ), respectively. Countries with the lowest prevalence of PBF were Gambia $(21.75 \%)$ in West Africa, Kenya (6.52\%) in East Africa, Gabon (19.62\%) in Central Africa and Lesotho $(8.25 \%)$ in Southern Africa.

\section{Bottle feeding}

A forest plot of the prevalence of BTLF for the 29 countries is shown in figure 5. The prevalence of BTLF for West Africa, East Africa, Central Africa and Southern Africa was $8.17 \%$ (95\% CI 5.51 to 10.84$), 14.32 \%(95 \%$ CI 7.62 to 21.03$), 17.01 \%$ (95\% CI 8.06 to 25.95$)$ and $30.05 \%$ (95\% CI 28.42 to 31.69 ), respectively. Countries with the lowest prevalence of BTLF were Burkina Faso $(1.66 \%)$ in West Africa, Burundi $(3.22 \%)$ in East Africa, Democratic Republic of Congo $(5.43 \%)$ in Central Africa and Lesotho $(23.50 \%)$ in Southern Africa.

\section{DISCUSSION}

This study categorised the 29 sub-Saharan African countries into four subregions, and carried out a meta-analysis 


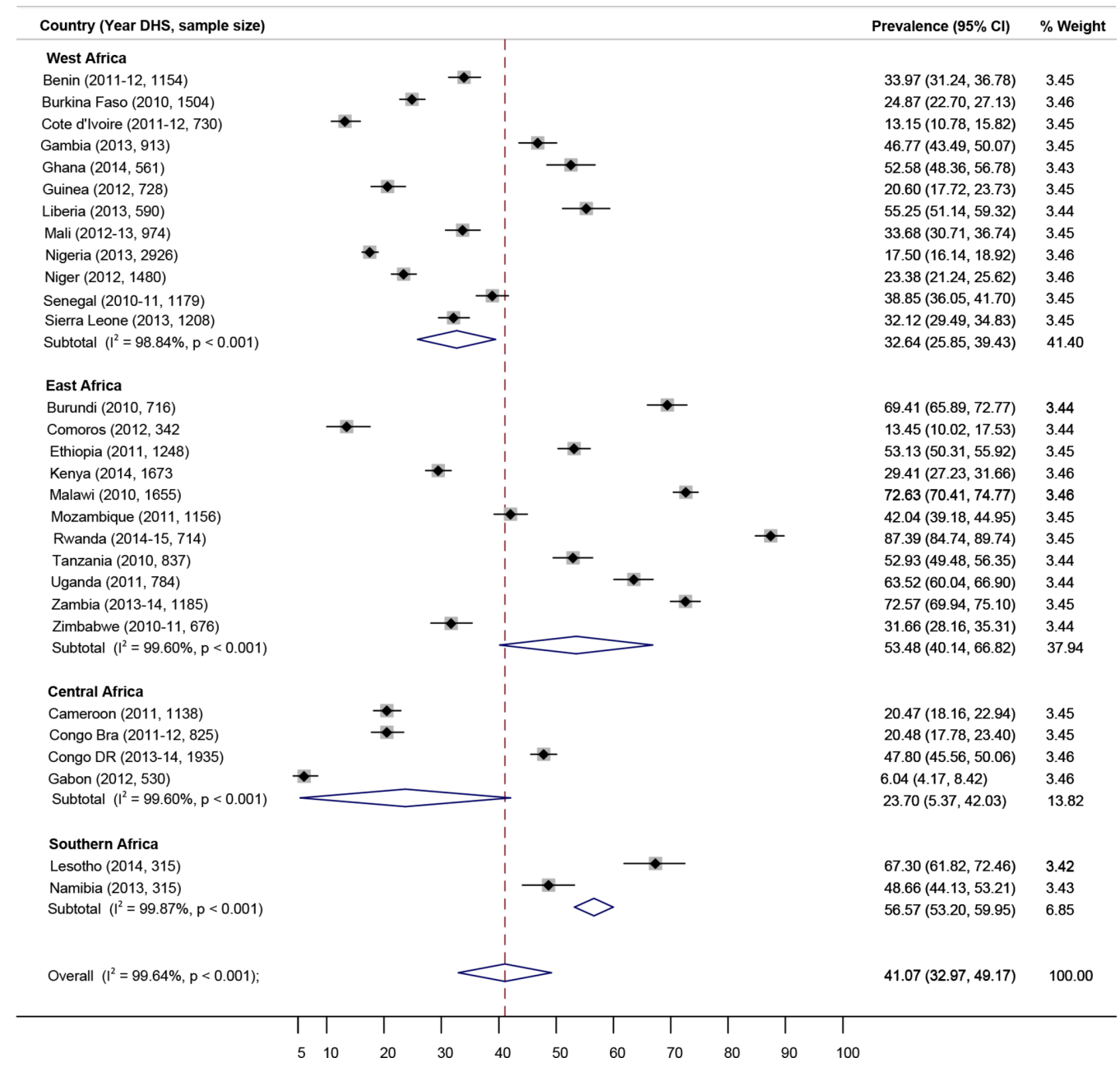

Figure 3 Prevalence of exclusive breast feeding in 28 sub-Saharan African countries (2010-2015). Congo Bra, Congo Brazzaville; Congo DR, Democratic Republic of Congo; DHS, Demographic and Health Surveys.

of the pooled/overall prevalence of each of the four key breastfeeding indicators $(E I B F, E B F, P B F$ and $B T L F)$ for each of the four subregions, namely West Africa, East Africa, Central Africa and Southern Africa. The majority of countries reported EIBF prevalence of more than $50 \%$, a target set by the $\mathrm{WHO},{ }^{34}$ and the overall EBF prevalence across the countries was less than $50 \%$. Only five countries reported $\mathrm{PBF}$ prevalence of less than $10 \%$, and the overall BTLF prevalence across the countries was more than $10 \%$.

There is evidence of the benefits of breast feeding for infant nutrition, development, reduced morbidity and mortality, and preventing long-term chronic diseases. ${ }^{45}$ The lower mortality risk is mainly due to reductions in deaths caused by infectious diseases, and this is most evident among infants who are given only breast milk (EBF) during the first 6 months. ${ }^{17}$ Additional benefits, which include the supply of colostrum or 'first milk', which contains proteins, carbohydrates, fats, vitamins, minerals and antibodies, which fight disease-causing agents such as bacteria and viruses, ${ }^{1}$ are provided by EIBF. Recent studies have revealed that EIBF and EBF are both associated with substantially lower neonatal mortality. ${ }^{23} 35$
Despite the benefits of EIBF and EBF, our study found that the overall/pooled prevalence of EIBF across the West and Central countries was lower than the WHO target of $50 \%$ by the year $2025 .^{34}$ As many as 11 countries recorded prevalence of less than $50 \%$. A low prevalence of EIBF has also been reported in other low-income countries such Bangladesh. ${ }^{36}$ Countries that reported the lowest prevalence of EIBF in our study included Guinea in West Africa and Congo Brazzaville in Central Africa. Further, the majority of countries in East Africa and Southern Africa recorded higher EIBF and EBF pooled prevalence than the overall value.

A number of sociodemographic factors have been found in past studies to be associated with delayed initiation of breast feeding and non-exclusive breast feeding. The main reasons given for failure to introduce babies to breast milk soon after delivery have been health-related; these include a mother not having sufficient breast milk. ${ }^{37}$ Cultural practices have been found to play a role in delayed initiation of breast feeding. For instance, in some settings in Nigeria, there is the belief that colostrum is 'dirty milk' and therefore harmful to the baby. In addition, it is believed that after delivery, 


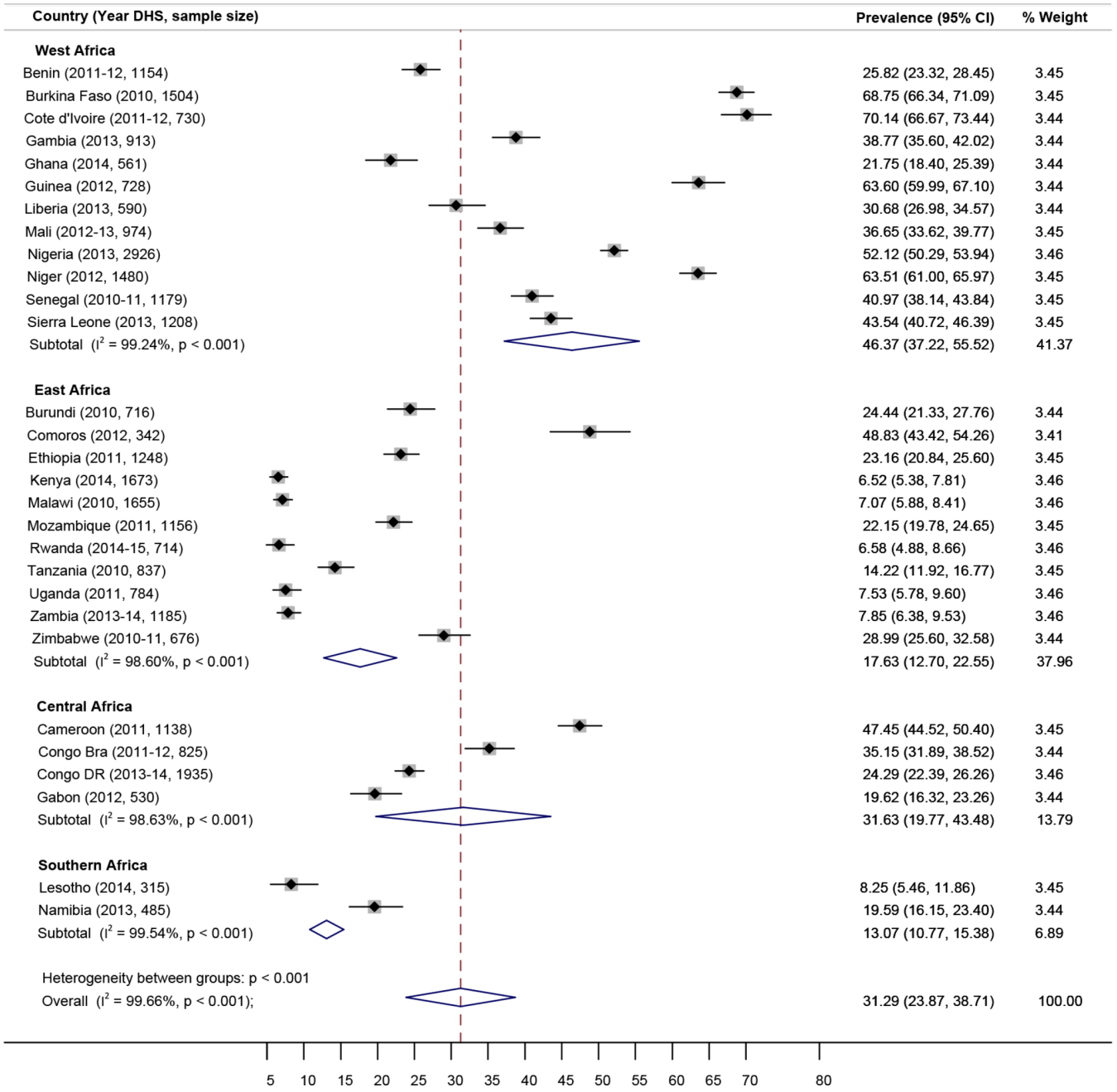

Figure 4 Prevalence of predominant breast feeding in 28 sub-Saharan African countries (2010-2015). Congo Bra, Congo Brazzaville; Congo DR, Democratic Republic of Congo; DHS, Demographic and Health Surveys.

the mother has to rest and clean up and some rituals and prayers have to be performed before breast feeding commences. ${ }^{38}$ Other factors found to be associated with non-EBF include the mother's marital status and level of education. There have been conflicting results ${ }^{37} 39$ in some past studies regarding the association between a mother's marital status and non-EBF. In one study, ${ }^{40}$ women who were not in union, especially those who were formerly married, were found to have higher odds of non-EBF than those who were in union. A plausible reason for this association may be due to the presence or absence of social, emotional and economic support of a partner. ${ }^{41}$ Further, mothers with no formal education have been found to have higher odds of non-EBF compared with those who had secondary education or higher. $^{40} 4243$

Our study found that the overall/pooled prevalence of PBF recorded in West and Central Africa was higher than the overall prevalence across all the 29 countries. For this indicator, a lower prevalence implies better infant feeding practice, as PBF has a risk effect on an infant's health. The WHO sets optimal breastfeeding prevalence at $90 \%$; therefore, it would be expected that the prevalence of PBF should be as close to $10 \%$ as possible. This may suggest that there were more effective interventions to discourage mothers from practising PBF in East and Southern Africa than in West and Central Africa. On the other hand, we found that the overall/pooled prevalence of BTLF was highest in Southern Africa. In particular, Mozambique was exceptional, as it recorded an alarmingly high prevalence of BTLF.

The overall prevalence of EIBF was highest in Southern Africa compared with the other subregions, and lowest in Central Africa. This is consistent with a recent Unicef report ${ }^{44}$ that found that the share of infants who are breast fed within 1 hour of birth ranges from around $40 \%$ in West and Central Africa to about $60 \%$ in East and Southern Africa. We found a similar pattern in the prevalence of EBF. East and Southern African countries fared better than their West and Central counterparts. The Unicef report ${ }^{44}$ noted that when data from five indicators relating to breast feeding are analysed regionally, children in West and Central Africa appear to be at a distinct disadvantage, in contrast to their peers in Eastern and Southern Africa. 


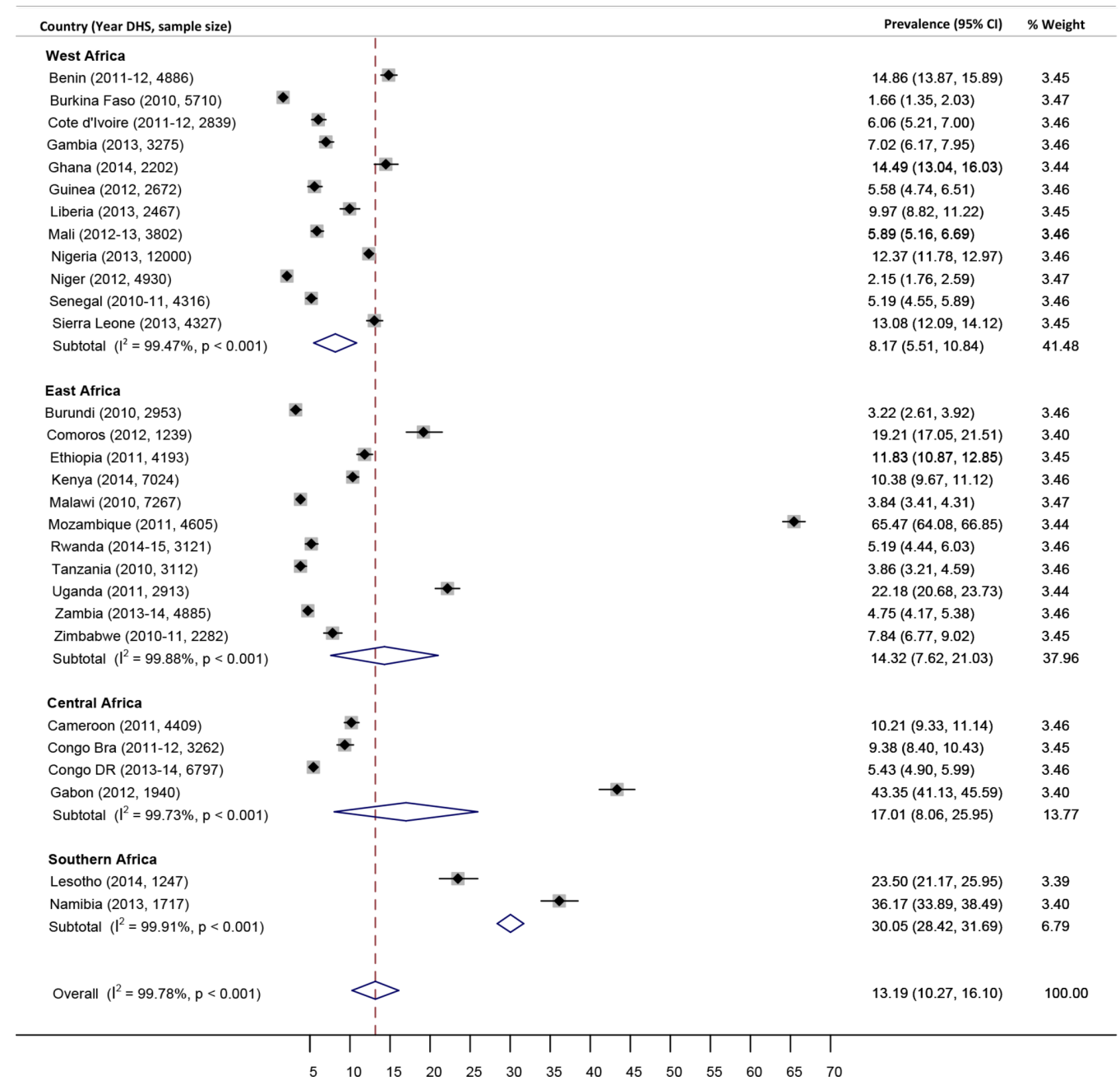

Figure 5 Prevalence of bottle feeding in 28 sub-Saharan African countries (2010-2015). Congo Bra, Congo Brazzaville; Congo DR, Democratic Republic of Congo; DHS, Demographic and Health Surveys.

The overall prevalence of PBF was found to be higher in West and Central Africa compared with Southern and East Africa, indicating that Southern and East African countries fared better in EBF than their West and Central African counterparts. In West and Central Africa, the greatest obstacle to EBF is plain water. ${ }^{44}$ The overall prevalence of BTLF was lower (better) in West and Central African countries compared with Southern and East African countries, indicating that West and Central African countries fared better in BTLF practices than their Southern and Central African counterparts.

The high prevalence of PBF in countries may be attributed to cultural beliefs. For instance in some settings, mothers or other relatives give water and other concoctions to infants, with the belief of quenching their thirst or 'welcoming' them into the world. ${ }^{45}{ }^{46}$ BTLF has been known to be practised for both justifiable (illness and breast illness) and unjustifiable (own choice, perceived lack of milk, low breast milk production) reasons. ${ }^{47}$ Prolonged BTLF of milk and other fermentable liquids in developed countries has been known to create a risk of otitis media, dental caries and speech difficulties. ${ }^{48}$ In less-developed countries, BTLF is especially prevalent among families of higher socioeconomic status and among working mothers. ${ }^{36}$

The aim of the Global Strategy for Infant and Young Child Feeding (IYCF) was to address, among others, appropriate breastfeeding practices. Through this programme, breast feeding of infants who are 6 months old or younger has increased in sub-Saharan Africa in the last 10 years. National strategies are being implemented by more than 30 out of the 46 countries in the African region of the $\mathrm{WHO} .^{49}$ The programme led to the implementation of a guide ${ }^{50}$ that offers countries appropriate methods of transforming the objectives of the global strategy into definite and defined policies, strategies and action plans for individual countries. The governments that have succeeded in translating the global strategy into national strategies did so by effectively coordinating and collaborating with relevant agencies and other stakeholders (both national and international). The strategy has been used as a guide in translating IYCF practices and also in setting annual targets in some countries including Nigeria. ${ }^{51}$

Our study has a number of strengths. First, prevalence of the four key breastfeeding indicators was based on 29 
nationally representative surveys, and therefore we could generalise our findings across the subregion. Second, the DHS variables are similarly defined across countries and thus comparable across the countries. The study, however, has a number of limitations. There could be a poor maternal recall of duration of breast feeding. ${ }^{52} \mathrm{~A}$ past research in the $\mathrm{USA}^{52}$ reported that mothers who breast fed their infants for shorter periods were more likely to have breastfeeding duration exaggerated, while the opposite was found to be true for mothers who breast fed for longer periods. In addition, DHS used a 24-hour recall method for estimating EBF rates, and although this method is recommended by the WHO it may lead to a considerable overestimation of EBF rates, as it does not include children who were given liquids and foods at infrequent intervals. ${ }^{53-56}$ Furthermore, the small number of countries in Southern Africa could introduce some information bias. Despite these limitations, our study has implications for policy.

\section{POLICY IMPLICATIONS AND CONCLUSIONS}

Promoting the practice of EIBF has the potential of making a key impact saving neonatal deaths. ${ }^{23}$ Intervention programmes to promote breast feeding should lay emphasis on the practice of EIBF and EBF. This is especially relevant to countries in sub-Saharan Africa, where there are high rates of neonatal and infant mortality, but $\mathrm{EBF}$ and PBF are already practised by most mothers. ${ }^{23}$

Community-based breastfeeding promotion programmes in sub-Saharan Africa should remain a priority, with renewed emphasis on early initiation in addition to exclusiveness and duration of breast feeding. These programmes should target the factors negatively associated with EIBF and EBF by ensuring accessible education for the female child, supporting and counselling of formerly married women and eschewing negative cultural practices. In addition, maternal leave duration should be reviewed in all countries to cater for working mothers to practise EBF.

In conclusion, our study revealed that West and Central Africa recorded low prevalence of the breastfeeding indicators. Therefore stakeholders in these subregions need to revamp interventions to improve breastfeeding practices among mothers. Further, appropriate interventions should target Southern African countries to discourage the practice of BTLF, as that subregion recorded the highest prevalence of this indicator.

Contributors All and KEA designed the study and performed the analysis. All prepared the manuscript. KEA and AMNR provided advice on the study design, data analysis and revision of the final manuscript. All authors read and approved the manuscript.

\section{Competing interests None declared.}

Ethics approval Our study used existing public domain survey data sets, which are freely available online with all identifier information removed. The first author sought permission and approval from MEASURE DHS/ICF International to download and use the data sets of the various countries examined.

Provenance and peer review Not commissioned; externally peer reviewed.
Data sharing statement There are no additional unpublished data from this study.

Open Access This is an Open Access article distributed in accordance with the Creative Commons Attribution Non Commercial (CC BY-NC 4.0) license, which permits others to distribute, remix, adapt, build upon this work non-commercially, and license their derivative works on different terms, provided the original work is properly cited and the use is non-commercial. See: http://creativecommons.org/ licenses/by-nc/4.0/

(C) Article author(s) (or their employer(s) unless otherwise stated in the text of the article) 2017. All rights reserved. No commercial use is permitted unless otherwise expressly granted.

\section{REFERENCES}

1. Unicef for child. Improving breastfeeding, complementary foods and feeding practices. https://www.unicef.org/nutrition/index breastfeeding.html

2. USAID. Nutrition in the first 1,000 days. New York, USA: USAID, 2012.

3. WHO. Exclusive breastfeeding. Nutrition. http://www.who.int/ nutrition/topics/exclusive breastfeeding/en/

4. León-Cava N, Lutter C, Ross J, et al. Quantifying the benefits of breastfeeding: a summary of the evidence. PAHO Washington, DC, 2002.

5. Horta BL, Bahl R, Martines JC, et al. Evidence on the long-term effects of breastfeeding: systematic reviews and meta-analyses. Geneva: World Health Organization, 2007.

6. WHO. Early initiation of breastfeeding to promote exclusive breastfeeding. http://www.who.int/elena/titles/early_breastfeeding/ en/

7. WHO. Part 1. Definitions. Indicators for assessing infant and young child feeding practices. Geneva: UNICEF, USAID, 2008.

8. NEOVITA Study Group. Timing of initiation, patterns of breastfeeding, and infant survival: prospective analysis of pooled data from three randomised trials. Lancet Glob Health 2016;4:e266-75.

9. Ladomenou F, Moschandreas J, Kafatos A, et al. Protective effect of exclusive breastfeeding against infections during infancy: a prospective study. Arch Dis Child 2010;95:1004-8.

10. Clemens J, Elyazeed RA, Rao M, et al. Early initiation of breastfeeding and the risk of infant diarrhea in rural Egypt. Pediatrics 1999;104:e3.

11. Kramer MS, Matush L, Vanilovich I, et al. Effects of prolonged and exclusive breastfeeding on child height, weight, adiposity, and blood pressure at age $6.5 \mathrm{y}$ : evidence from a large randomized trial. Am J Clin Nutr 2007;86:1717-21.

12. Park J, Kim HS, Chu SH, et al. The effect of predominant breastfeeding on the risk of obesity in Korean preschool children. Nurs Health Sci 2015;17:77-83.

13. McCormick E. The Negative Effects of Bottle Feeding. 2016. http:// www.livestrong.com/article/542846-the-negative-effects-of-bottlefeeding/

14. Unicef for every child. Breastfeeding. https://www.unicef.org/ nutrition/index_24824.html

15. Debes AK, Kohli A, Walker N, et al. Time to initiation of breastfeeding and neonatal mortality and morbidity: a systematic review. BMC Public Health 2013;13(Suppl 3):S19.

16. Black RE, Victora CG, Walker SP, et al. Maternal and child undernutrition and overweight in low-income and middle-income countries. Lancet 2013;382:427-51.

17. Black RE, Allen LH, Bhutta ZA, et al. Maternal and child undernutrition: global and regional exposures and health consequences. Lancet 2008;371:243-60.

18. Setegn T, Gerbaba M, Belachew T. Determinants of timely initiation of breastfeeding among mothers in Goba Woreda, South East Ethiopia: A cross sectional study. BMC Public Health 2011;11:1.

19. Morhason-Bello IO, Adedokun BO, Ojengbede OA. Social support during childbirth as a catalyst for early breastfeeding initiation for first-time Nigerian mothers. Int Breastfeed J 2009;4:16.

20. Tawiah-Agyemang C, Kirkwood BR, Edmond K, et al. Early initiation of breast-feeding in Ghana: barriers and facilitators. J Perinatol 2008;28(Suppl 2):S46-52.

21. Horii N, Guyon AB, Quinn VJ. Determinants of delayed initiation of breastfeeding in rural Ethiopia: programmatic implications. Food Nutr Bull 2011;32:94-102.

22. Awi DD, Alikor EA. Barriers to timely initiation of breastfeeding among mothers of healthy full-term babies who deliver at the University of Port Harcourt Teaching Hospital. Niger J Clin Pract 2006;9:57-64. 
23. Edmond KM, Zandoh C, Quigley MA, et al. Delayed breastfeeding initiation increases risk of neonatal mortality. Pediatrics 2006;117:e380-6.

24. The Hunger Project. The Epicenter Strategy. https://www.reference. com/geography/many-countries-africa-6d064c6831667ac9 (accessed 8 Jan 2017).

25. UNDP Africa. About Sub-Saharan Africa. http://www.africa.undp.org/ content/rba/en/home/regioninfo.html (accessed 18 Jan 2017).

26. The World Bank. Sub-Saharan Africa. http://data.worldbank.org/ region/sub-saharan-africa (accessed 8 Jan 2017).

27. DHSProgram. Data collection. http://dhsprogram.com/data/datacollection.cfm

28. The Demographic and Health Surveys (DHS) Program. http:// dhsprogram.com/What-We-Do/Survey-Types/DHS-Methodology.cfm

29. World Health Organization. part 1-definitions: conclusions of a consensus meeting held 6-8 November 2007 in Washington DC. Indicators for assessing infant and young child feeding practices. USA, Geneva: WHO, 2008.

30. Nyaga VN, Arbyn M, Aerts M. Metaprop: a stata command to perform meta-analysis of binomial data. Arch Public Health 2014;72:1.

31. Freeman MF, Tukey JW. Transformations related to the angular and the square root. Ann Math Stat 1950;21:607-11.

32. Brown LD, Cai TT, DasGupta A. Interval estimation for a binomial proportion. Stat sci 2001:101-17.

33. Patsopoulos NA, Evangelou E, loannidis JP. Sensitivity of betweenstudy heterogeneity in meta-analysis: proposed metrics and empirical evaluation. Int J Epidemiol 2008;37:1148-57.

34. WHO. Global nutrition targets 2025. http://www.who.int/nutrition/ global-target-2025/en/

35. Mullany LC, Katz J, Li YM, et al. Breast-feeding patterns, time to initiation, and mortality risk among newborns in southern Nepal. J Nutr 2008;138:599-603.

36. Mihrshahi S, Kabir I, Roy SK, et al. Determinants of infant and young child feeding practices in Bangladesh: secondary data analysis of Demographic and Health Survey 2004. Food Nutr Bull 2010;31:295-313.

37. Thulier D, Mercer J. Variables associated with breastfeeding duration. J Obstet Gynecol Neonatal Nurs 2009;38:259-68.

38. Davies-Adetugbo AA. Sociocultural factors and the promotion of exclusive breastfeeding in rural Yoruba communities of Osun State, Nigeria. Soc Sci Med 1997;45:113-25.

39. Scott JA, Binns CW. Factors associated with the initiation and duration of breastfeeding: a review of the literature. Breastfeed Rev 1999; $7: 5-16$

40. Kimani-Murage EW, Madise NJ, Fotso JC, et al. Patterns and determinants of breastfeeding and complementary feeding practices in urban informal settlements, Nairobi Kenya. BMC Public Health 2011;11:396.
41. Giugliani ERJ. Breast-feeding: how and why to promote it. $J$ Pediatr 1994:70:138-51.

42. Pascale KNA, Laure NJ, Enyong OJ. Factors associated with breast feeding as well as the nutritional status of infants (0-12) Months: An Epidemiological Study in Yaounde, Cameroon. Pakistan J Nutr 2007;6:259-63.

43. Akter S, Rahman MM. The determinants of early cessation of breastfeeding in Bangladesh. World Health Popul 2010;11:5-12.

44. UNICEF. Infant feeding. https://data.unicef.org/topic/nutrition/infantand-young-child-feeding/\# (accessed 8 Mar 2017).

45. Otoo GE, Lartey AA, Pérez-Escamilla R. Perceived incentives and barriers to exclusive breastfeeding among periurban Ghanaian women. J Hum Lact 2009;25:34-41.

46. IDDRISU S. Exclusive breastfeeding and family influences in rural Ghana: a qualitative study, 2013.

47. Kruger R, Gericke GJ. A qualitative exploration of rural feeding and weaning practices, knowledge and attitudes on nutrition. Public Health Nutr 2003;6:217-23.

48. Bonuck KA, Kahn R. Prolonged bottle use and its association with iron deficiency anemia and overweight: a preliminary study. Clin Pediatr 2002;41:603-7.

49. WHO. Infant and young child feeding. www.aho.afro.who.int/en/ahm/ issue/14/reports/implementation-global-strategy-infant-and-youngchild-feeding-national-level (accessed 19 Jan 2017).

50. WHO. Infant and Young Child Feeding. Guide for national implementation of the global strategy for infant and young child feeding. WHO, 2004

51. Federal Ministry of Health N. National policy on infant and young child feeding in Nigeria. Abuja, Nigeria: Federal Ministry of Health, Nutrition Division, 2005

52. Promislow JH, Gladen BC, Sandler DP. Maternal recall of breastfeeding duration by elderly women. Am J Epidemiol 2005;161:289-96.

53. Aarts C, Kylberg E, Hörnell A, et al. How exclusive is exclusive breastfeeding? A comparison of data since birth with current status data. Int J Epidemiol 2000;29:1041-6.

54. Ssenyonga R, Muwonge R, Nankya I. Towards a better understanding of exclusive breastfeeding in the era of HIV/AIDS: a study of prevalence and factors associated with exclusive breastfeeding from birth, in Rakai,Uganda. $J$ Trop Pediatr 2004:50:348-53.

55. Engebretsen IM, Wamani $\mathrm{H}$, Karamagi $\mathrm{C}$, et al. Low adherence to exclusive breastfeeding in Eastern Uganda: a community-based cross-sectional study comparing dietary recall since birth with 24hour recall. BMC Pediatr 2007;7:10.

56. Hazir T, Akram DS, Nisar YB, et al. Determinants of suboptimal breast-feeding practices in Pakistan. Public Health Nutr 2013;16:659-72. 